$\left|\frac{5}{2}\right|_{\text {LA-5196-MS }}$

INFORMAL REPORT

\section{Scattering Formulas for the Two-Particle Reaction}


This report was prepared as an account of work sponsored by the United States Government. Neither the United States nor the United States Atomic Energy Commission, nor any of their employees, nor any of their contrac. tors, subcontractors, or their employees, makes any warranty, express or implied, or assumes any legal liability or responsibility for the accuracy, completeness or usefulness of any information, apparatus, product or process disclosed, or represents that its use would not infringe privately owned rights.

In the interest of prompt distribution, this LAMS report was not edited by the Technical Information staff.

Printed in the United States of America. Available from

National Technical Information Service

U. S. Department of Commerce

5285 Port Royal Road

Springfield, Virginia 22151

Price: Printed Copy \$3.00; Microfiche $\$ 0.95$ 
LA-5196-MS

Informal Report

UC-32 \& 34

ISSUED: February 1973

\section{Scattering Formulas for the Two-Particle Reaction}

by

C. J. Everett

E. D. Cashwell

NOTICE

This report was prepated as an account of work sponsored by the United States Government. Neither the United States nor the United States Atomic Energy Commission, nor any of their employees, nor any of their contractors, subcontractors, or their employees, makes any warranty, express or implied, or essumes any

legal lisbility or responsibility fot the accuracy, com-

pleteness or usefulness of any information, apparatus,

product or process disclosed, or represents that its use

would not infringe privately owned rights. 
SCATTERING FORMULAS

FOR THE TWO-PARTICLE REACTION

by

C. J. Everett and E. D. Cashwe11

ABSTRACT

After a general (non-relativistic) treatment of transmutation resulting in two particles, the formulas obtained are specialized to give the laboratory energy-angle dependence for the inelastic $\left(n, n^{\prime}\right)$-reaction and the elastic $(n, n)$-collision, in a form adapted to computation. These results are required for Monte Carlo neutron codes when the differential cross sections for such reactions are given in the laboratory frame, and in any case, for the "point detector" routine.

\section{PARAMETERS OF A SYSTEM}

Let $S$ be a system of particles 1 , with velocitles $v_{1}$. rest masses $m_{1}>0$, rest energies $e_{1}=m_{1} c^{2}$, momenta $P_{1}=m_{1} v_{1}$, and kinetic energies $k_{i}=\frac{1}{2} m_{1} v_{i}^{2}$; and with the totals

$m_{S}=\sum m_{1} \quad e_{S}=\sum e_{i} \quad P_{S}=\sum P_{i} \quad k_{s}=\sum k_{i}$

The velocity of its center of mass (CM) is then

$$
v_{s}=\sum \frac{m_{1}}{m_{s}} v_{1}
$$

whence

$$
{ }^{m} \mathbf{s}_{s}=P_{s}
$$

The velocities relative to the $C M$ being

$$
v_{1}^{\prime}=v_{1}-v_{s}
$$

1t follows that

$$
\mathrm{p}_{\mathrm{S}}^{\prime} \equiv \sum \mathrm{m}_{1} \mathrm{v}_{1}^{\prime}=0 \quad \mathrm{k}_{\mathrm{S}}^{\prime} \equiv \sum \frac{1}{2} \mathrm{~m}_{1} v_{1}^{-2}=\mathrm{k}_{\mathrm{S}}-\frac{1}{2} \mathrm{~m}_{\mathrm{s}} \mathrm{v}_{\mathrm{S}}^{2}
$$

From Fig. 1, one verifies the LAB/CM transformation

$$
\begin{aligned}
& v_{1}^{2}=v_{s}^{2}+v_{1}^{-2}+2\left|v_{s}\right|\left|v_{1}^{\prime}\right| a_{1}^{\prime} ; a_{1}^{\prime} \equiv \cos \psi_{1}^{\prime} \\
& a_{1}=\left\{\left|v_{s}\right|+\left|v_{1}^{-}\right| a_{1}^{-}\right\} /\left|v_{1}\right| ; a_{1} \equiv \cos \psi_{1}
\end{aligned}
$$

which may be written as

$$
\begin{aligned}
& v_{i}^{2} / v_{s}^{\prime}=\left(1+v_{i}^{-2} / v_{s}^{2}\right)+2 a_{1}^{\prime}\left(\left|v_{1}^{-}\right| /\left|v_{s}\right|\right) \\
& a_{i}=\left(1+a_{1}^{-}\left|v_{1}^{-}\right| /\left|v_{s}\right|\right) /\left(\left|v_{1}\right| /\left|v_{s}\right|\right)
\end{aligned}
$$

With the obvious identifications, these are of the form $x^{2}=\left(1+B^{2}\right)+2 a_{1}^{-} B, a_{1} x=1+a_{1}^{\prime} B$, from which $a_{1}^{\prime}$ may be eliminated, with the result $x=a_{1}$ $\pm\left\{a_{1}^{2}-\left(1-B^{2}\right)\right\}^{1 / 2}$, or expllcitly

$$
\left|v_{1}\right| /\left|v_{s}\right|=a_{1} \pm\left(a_{1}^{2}-k\right)^{1 / 2} ; k-1-v_{1}^{-2} / v_{s}^{2}<1
$$

Note that, if $\left|v_{1}^{-}\right|$and $\left|v_{S}\right|$ ar prescribed (as they may be when $S$ results from a transmutation), there are the three possible cases of $\mathrm{Fig}_{\mathrm{g}} \mathrm{2}$. Cases I, II, III are distingulshed by the Inequalities

$$
\left|v_{1}\right| \leqq\left|v_{s}\right| \text { or } 0 \leqq k
$$




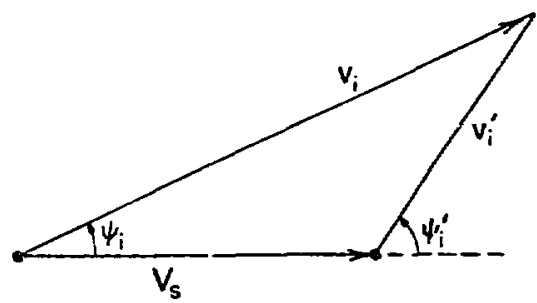

F1g. 1 .

In Case $I$, it is apparent from the figure that the limfting LAB angle $\bar{\psi}_{1}$ has sin $\bar{\psi}_{1}=\left|v_{1}\right| /\left|v_{s}\right|$, or equivalently, $\bar{a}_{i} \equiv \cos \bar{\psi}_{1}=\sqrt{k}$. For a given LAB cosine $a_{1}=\cos \psi_{1}$, there are two possible LAB speeds $\left|v_{1}\right|$; and therefore 1 it is clear that both signs ( \pm ) are required in ( 8 ).

In Case II, equations (6-8) take the simple form $v_{1}^{2} / v_{s}^{2}=2\left(1+a_{1}^{-}\right), a_{1}=\left\{\frac{1}{2}\left(1+a_{1}^{-}\right)\right\}^{1 / 2}$, $\left|v_{1}\right| /\left|v_{s}\right|=2 a_{1}$. Note that $\cos \psi_{1}=\cos \left(\psi_{1}^{\prime} / 2\right)$, and $\psi_{1}=\psi_{1}^{\prime} / 2$, a relation obvious in Fig. 2 . The limiting $L A B$ angle is $\pi / 2$.

In Case IJI, $i v_{I} \mid$ is again uniquely determined by $a_{1}$, which now ranges over the entire interval $[-1,1]$, and the $(+)$ sign is mandatory in (8), since $\mathbf{K}<0$.

In terms of energy, equations (6-8) and their properties are summarized in the following:

$$
\begin{aligned}
& k_{1} / k_{1}^{*}=1+\left(k_{1}^{-} / k_{1}^{*}\right)+2 a_{1}^{-}\left(k_{1}^{-} / k_{1}^{*}\right)^{1 / 2} ; \\
& k_{1}^{*} \equiv \frac{1}{2} m_{1} v_{s}^{2} \\
& a_{1}=\left\{1+a_{1}^{*}\left(k_{1}^{-} / k_{1}^{*}\right)^{1 / 2}\right\} /\left(k_{1} / k_{1}^{*}\right)^{1 / 2}
\end{aligned}
$$

$k_{1} / k_{1}^{*}=\left\{a_{1} \pm\left(a_{1}^{2}-k\right)^{1 / 2}\right\}^{2} ; k=1-k_{1}^{*} / k_{1}^{*}$

Case I. $k_{1}^{\prime}<k_{1}^{*} ;( \pm)$ in (11),

$$
\bar{a}_{1}-\sqrt{k} \leqslant a_{1} \leqslant 1
$$

Case II. $k_{1}^{\prime}=k_{1}^{*}, k_{1} / k_{1}^{*}=2\left(I+a_{3}^{\prime}\right)$

$a_{1}=\left|\frac{1}{2}\left(1+a_{1}^{\prime}\right)\right|^{1 / 2}, k_{1} / k_{1}^{*}=4 a_{1}^{2}, 0<a_{1}<1$.

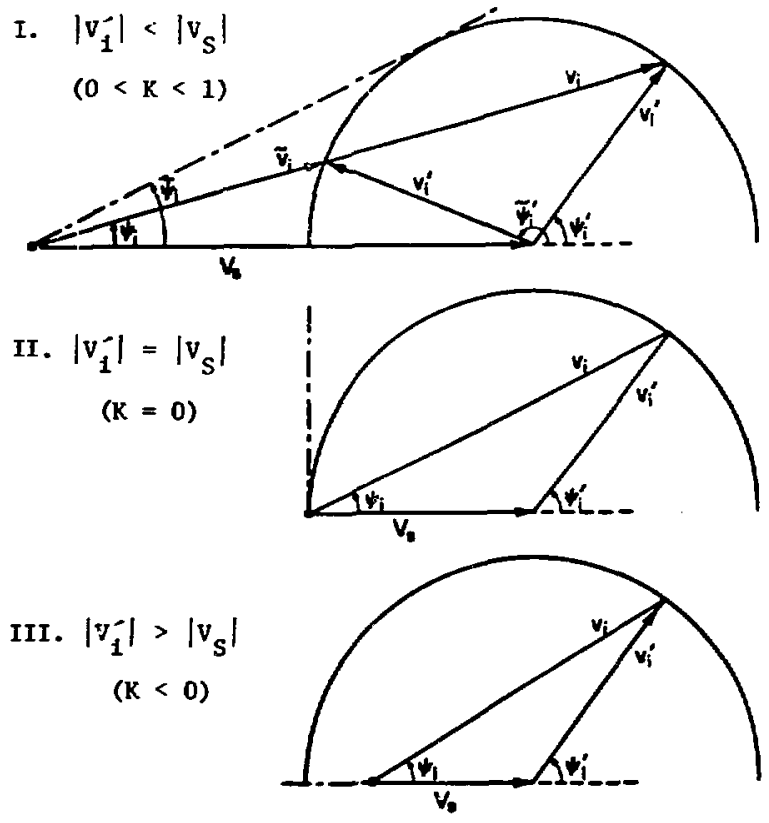

Fig. 2 .

Case III. $k_{1}^{-}>k_{1}^{*} ;(+)$ In $(11),-1 \leqslant a_{1} \leqslant 1$.

If $s$ consists of just two particles $1=3,4$, with specifled $m_{3}, m_{4}, k_{5}^{j}$, then $k_{3}^{j}, k_{4}^{j}$ are aniquely determined in the (CM) frame by the equations $k_{3}^{j}+k_{4}^{-}$ $=k_{s^{2}}^{*} P_{3}^{-}+P_{4}^{-}=0$. For we then have

$$
m_{3} v_{3}^{-2}+m_{4} v_{4}^{-2}=2 k_{s}^{-}
$$

$$
m_{3}^{2} v_{3}^{-2}-m_{4}^{2} v_{4}^{-2}=0
$$

and consequently $m_{s} m_{3} \nabla_{3}^{-2}=2 m_{4} k_{s}^{*}, m_{s} m_{4} v_{4}^{-2}=2 m_{3} k_{s}^{*}$, that is,

$$
k_{3}^{\prime}=\frac{m_{4}}{m_{s}} k_{s}^{\prime} \quad k_{4}^{-}=\frac{m_{3}}{m_{s}} k_{s}^{\prime}
$$

\section{TRANSMUTATION}

A transmutation

$$
A \rightarrow S
$$

of such a general system $A$ of particles $h$, into a second system $S$ of particles 1 , is governed (in nonrelativistic approximation) by the three conservation 
laws

$\mathrm{m}_{\mathrm{A}}=\mathrm{m}_{\mathrm{S}}(\equiv \mathrm{m}) \quad \mathrm{P}_{\mathrm{A}}=\mathrm{P}_{\mathrm{S}} \quad \mathrm{k}_{\mathrm{A}}+\mathrm{e}_{\mathrm{A}}=\mathrm{k}_{\mathrm{S}}+\mathrm{e}_{\mathrm{S}}$

where the first ignores changes ir total rest mass, and the third does not. The conservation of energy may be expressed in the form

$$
k_{A}+Q=k_{S}
$$

where

$$
Q \equiv e_{A}-e_{S}
$$

is the "Q-value" of the reaction.

These laws, together with the relations (3), (5), for both $A$ and $S$, imply that

$$
v_{A}=v_{S}(\equiv v)
$$

1.e., the $C M$ velocity is unchanged, and hence the reaction in the common $C M$ frame is governed by the laws

$$
k_{A}^{\prime}+Q=k_{S}^{\prime} \quad P_{A}^{\prime}=0=P_{S}^{\prime}
$$

The first equation implies the necessary (and sufficient) condition

$$
k_{A}^{\prime}>(-Q)
$$

for the transmutation to be mechanically possible.

If $S$ is a two-particle system, its CM kinetic energies are necessarily those in (16), where $k_{S}^{\prime}=k_{A}^{\prime}+Q$ is determined by the system $A$ and the $e_{1}$ of $s$.

III. TWO-PARTICLE REACTIONS WITH "TARGET AT REST" We consider here only the case of transmutations $A \rightarrow S$, where $A$ consists of two particles $h=1,2$, with the target 2 at rest $\left(v_{2}=0\right)$, and $s$ consists also of just two particles $1=3,4$.

For the system $A$, we find from (2), (4) (since $v_{2}=0$ )

$v \equiv v_{A}=\frac{m_{1}}{m} v_{1}, v_{1}^{\prime}=\frac{m_{2}}{m} v_{1}, v_{2}^{\prime}=-\frac{m_{1}}{m} v_{1} ;$ and therefore

$$
k_{1}^{\prime}=\frac{m_{2}^{2}}{m^{2}} k_{1} \quad k_{2}^{\prime}=\frac{m_{1} m_{2}}{m^{2}} k_{1} \quad k_{A}^{\prime}=\frac{m_{2}}{m} k_{1}
$$

The condition (22) now reads

$$
k_{1} \geqslant \frac{m}{m_{2}}(-Q) \equiv k_{T}
$$

where $k_{T} \leqq 0$ is the (k.e.) threshold for the reaction. Since $k_{1}>0$, this is restrictive only when $\mathrm{Q}<0$, 1.e., $e_{A}<e_{S^{*}}$ (We use $k_{T}$ in general as a convenient parameter.)

Supposing the reaction possible, we find from $(16,21,24)$ that the energy $k_{3}^{\prime}$ is uniquely determined as

$$
k_{3}^{\prime}=\frac{m_{2} m_{4}}{m^{2}} k_{1}\left(1-k_{T} / k_{1}\right)
$$

Moreover, the relation $v=\frac{m_{1}}{m} v_{1}$ of (23) implies

$$
k_{3}^{*} \equiv \frac{1}{2} m_{3} v^{2}=\frac{m_{1} m_{3}}{m^{2}} k_{1}
$$

Substitution of (26), (27) in (9-14) then yields, for $i=3$, the following summary for the present reaction:

$$
\begin{aligned}
& \frac{m^{2}}{m_{1} m_{3}}\left(k_{3} / k_{1}\right)=\left(1+\frac{m_{2} m_{4}}{m_{1} m_{3}}\right)-\frac{m_{2} m_{4}}{m_{1} m_{3}}\left(k_{T} / k_{1}\right) \\
& \quad+2 a_{3}^{\prime}\left|\frac{m_{2} m_{4}}{m_{1} m_{3}}\left(1-k_{T} / k_{1}\right)\right|^{1 / 2} ; k_{T}=\frac{m}{m_{2}}(-Q) \leqq 0
\end{aligned}
$$

$a_{3}=\left\{1+a_{3}^{-}\left[\frac{m_{2} m_{4}}{m_{1} m_{3}}\left(1-k_{T} / k_{1}\right)\right]^{1 / 2}\right\}$

$\int\left|\frac{m^{2}}{m_{1} m_{3}}\left(k_{3} / k_{1}\right)\right|^{1 / 2}$

$\mathbf{m} \equiv \mathbf{m}_{\mathbf{A}}$ 
$\frac{m^{2}}{m_{1} m_{3}}\left(k_{3} / k_{1}\right)=\left\{a_{3} \pm\left.\left(a_{3}^{2}-k\right)^{1 / 2}\right|^{2} ;\right.$

$$
K=1-\frac{m_{2} m_{4}}{m_{1} m_{3}}\left(1-k_{T} / k_{1}\right)=\frac{m m_{4}}{m_{1} I_{3}}\left(\frac{-0}{k_{1}}\right)-\frac{m\left(m_{4}-m_{1}\right)}{m_{1} m_{3}}
$$

Case I. $k_{1}\left(m_{4}-m_{1}\right)<m_{4}(-Q) ;( \pm)$ in (30),

$$
\bar{a}_{3}=\sqrt{k} \leqslant a_{3} \leqslant 1
$$

Case II. $k_{1}\left(m_{4}-m_{1}\right)=m_{4}(-Q) ; a_{3}=\left|\frac{1}{2}\left(1+a_{3}^{\prime}\right)\right|^{1 / 2}$,

$$
\begin{aligned}
& 0 \leqslant a_{3} \leqslant 1,2\left(1+a_{3}^{\prime}\right)=\frac{m^{2}}{m_{1} m_{3}}\left(k_{3} / k_{1}\right) \\
& =4 a_{3}^{2}
\end{aligned}
$$

Case III. $k_{1}\left(m_{4}-m_{1}\right)>m_{4}(-Q) ;(+)$ in $(30)$,

$$
-1 \leqslant a_{3} \leqslant 1
$$

In obtaining (30-33) we have used the definttion $k_{T}=\frac{m}{m_{2}}(-Q)$, and the identity

$$
m_{2} m_{4}-m_{1} m_{3}=m\left(m_{4}-m_{1}\right)
$$

We note here that whenever $m_{4}>m_{1}$, the $1 n-$ equalities distinguishing the three cases may be written as

$$
k_{1} \leqslant \frac{m_{4}}{m_{4}-m_{1}}(-Q)
$$

and if moreover $Q<0$, then all three cases are possible, Case I obtaining in the incident energy interval

$$
k_{T}=\frac{m}{m_{2}}(-Q)<k_{1}<\frac{m_{4}}{m_{4}-m_{1}}(-Q)
$$

which is non-vacuous since $m\left(m_{4}-m_{1}\right)=m_{2} m_{4}$

$-m_{1} m_{3}<m_{2} m_{4}$.
Again, if $m_{4}>m_{1}$, and $Q \geqslant 0$, then necessarily $k_{1}>0 \geqslant \frac{m_{4}}{m_{4}-m_{1}}(-Q)$, and Case III prevails.

IV. THE $\left(n, n^{\circ}\right)$ REACTION

We apply the foregoing results to an inelastic $\left(n, n^{\prime}\right)$ reaction, of form

$$
\begin{gathered}
n+\left(\begin{array}{l}
A \\
Z
\end{array}\right) \rightarrow \\
1
\end{gathered}
$$

In which an Incident neutron scatters from a nucleus at rest, leaving the latter in an exclted state. In such a case, we assume

$$
m_{1}=m_{3}<m_{2}=m_{4} \quad Q=e_{2}-e_{4}<0
$$

$-Q$ being the energy level excited. In terms of the usual parameter $A=m_{2} / m_{1}$, relations $(28-33)$ reduce to

$$
\begin{aligned}
& (A+1)^{2}\left(k_{3} / k_{1}\right)=1+A^{2}-A^{2}\left(k_{T} / k_{1}\right) \\
& +2 a \ddot{3}^{A} A\left(1-k_{T} / k_{1}\right)^{1 / 2} ; k_{T}=\frac{A+1}{A}(-Q)>0, \\
& A=m_{2} / m_{1}>1 \\
& a_{3}=\left\{1+a_{3}^{-A}\left(1-k_{T} / k_{1}\right)^{1 / 2}\right\} /(A+1)\left(k_{3} / k_{1}\right)^{1 / 2}
\end{aligned}
$$

$$
\begin{aligned}
& (A+1)^{2}\left(k_{3} / k_{1}\right)=\left\{a_{3} \pm\left(a_{3}^{2}-k\right)^{1 / 2}\right\}^{2} ; \\
& K=A(A+1)\left(-Q / k_{1}\right)-\left(A^{2}-1\right)
\end{aligned}
$$

Case I. $k_{T}=\frac{A+1}{A}(-Q)<k_{1}<\frac{A}{A-1}(-Q)$;

$$
\text { ( } \pm \text { ) In (37), } \bar{a}_{3}=\sqrt{k}<a_{3}<1
$$

Case II. $k_{1}=\frac{A}{A-1}(-Q), a_{3}=\left|\frac{1}{2}\left(1+a_{3}^{\prime}\right)\right|^{1 / 2}$,

$$
\begin{aligned}
& 0<a_{3} \leqslant 1,2\left(1+a_{3}^{\prime}\right)=(A+1)^{2}\left(k_{3} / k_{1}\right) \\
& =4 a_{3}^{2}
\end{aligned}
$$


Case III. $k_{1}>\frac{A}{A-1}(-Q) ;(+)$ in (37),

$$
-1 \leqslant a_{3} \leqslant 1
$$

All three cases are possible, depending on the incident energy.

v. ELASTIC COLLISION

In an elastic collision

$$
\begin{aligned}
& \mathrm{n}+\left(\begin{array}{l}
\mathrm{A}) \\
\mathrm{Z} !
\end{array}+\mathrm{n}+\left(\begin{array}{l}
\mathrm{A} \\
\mathrm{Z}
\end{array}\right)\right. \\
& \begin{array}{llll}
1 & 2 & 3 & 4
\end{array}
\end{aligned}
$$

one has

$$
\mathrm{m}_{1}=\mathrm{m}_{3} \leqslant \mathrm{~m}_{2}=\mathrm{m}_{4}, \quad \mathrm{Q}=0=\mathrm{k}_{\mathrm{T}}
$$

and sees from (31-33) that Cases I, II, III are now distinguished by the inequalities

$$
k_{1}(A-1) \lesseqgtr 0 ; A \equiv m_{2} / m_{1}
$$

Hence, for all nuclei but $H$, we have $A>1$ and Case III prevails, formulas (28-30) being

$$
\begin{aligned}
& (A+1)^{2}\left(k_{3} / k_{1}\right)=1+A^{2}+2 A a_{3}^{\prime} A=m_{2} / m_{1}>1 \text { (43) } \\
& a_{3}=\left\{1+A a_{3}^{-}\right\} /(A+1)\left(k_{3} / k_{1}\right)^{1 / 2} ;-1 \leqslant a_{3} \leqslant 1(44) \\
& (A+1)^{2}\left(k_{3} / k_{1}\right)=\left\{a_{3}+\left(a_{3}^{2}-k\right)^{1 / 2}\right\}^{2} ; \\
& K=1-A^{2}<0 .
\end{aligned}
$$

Finally, for hydrogen $(H)$ we assume $A=1$, and see from (42) that Case II obtains for all incldent energies $k_{1}$. The corresponding relations (32) then have the simple form

$k_{3} / k_{1}=\frac{1}{2}\left(1+a_{3}^{\prime}\right) ;-1 \leqslant a_{3}^{-} \leqslant 1 \quad(A=1)$

$$
a_{3}=\left|\frac{1}{2}\left(1+a_{3}\right)\right|^{1 / 2} ; 0 \leqslant a_{3} \leqslant 1
$$

$$
k_{3} / k_{1}=a_{3}^{2}
$$

As always in Case II, $\psi_{3}=\psi_{3} / 2$ with $\frac{\pi}{2}>\psi_{3}>0$.

\section{REFERENCES}

1. E. D. Cashwell, C. J. Everett, A Pract1cal Manual on the Monte Carlo Method (Pergamon Press, New York, 1959), Ch. V.

2. R. D. Evans, The Atomic Nucleus (Mc-Graw-H111 Book Co., Inc., New York, 1955), pp. 410-416. 